1 PhD. Department of Dentistry, Federal University of Rio Grande do Sul, Ramiro Barcelos Street, 2492 90035-004 - Porto Alegre, Brazil.

${ }^{2}$ DDS. Department of Dentistry, Federal University of Rio Grande do Sul, Ramiro Barcelos Street, 2492 90035-004 - Porto Alegre, Brazil.

${ }^{3}$ MSC, DDS. Department of Dentistry, State University of Maringá, Mandacaru Avenue, 1550 . 87080-000 - Maringá, Brazil.

4 PhD. Department of Dentistry, Federal University of Rio Grande do Sul, Ramiro Barcelos Street, 2492 90035-004 - Porto Alegre, Brazil.

${ }^{5}$ Radiologist doctor, Private clinic Freitas and Castro Street, 481 90040-401 - Porto Alegre, Brazil

Corresponding author: Eduardo Grossmann Faculty of Dentistry, Federal University of Rio Grande do Sul, Ramiro Barcelos Street, 2492 90035-004 - Porto Alegre, Brazil. Phone: (+55 51) 3331-4692 E-mail: grossmanneduardo@gmail.com

Received: May 30, 2018

Accepted: October 24,2018

\section{Prevalence of internal derangements of temporomandibular joint in patients with cleft-lip/palate}

\author{
Eduardo Grossmann', Thales Botomé Cousen², \\ Rodrigo Lorenzi Poluha ${ }^{3}$, Marcus Vinícius Martins \\ Collares $^{4}$, Enio Setogutti ${ }^{5}$
}

Aim: The aim of this study was to estimate the prevalence of internal derangements (ID) of temporomandibular joint (TMJ) in patients with cleft-lip/palate. Also, to evaluate the correlation of diagnosis between Research Diagnostic Criteria for temporomandibular disorders (RDC/TMD) clinical examination and Magnetic resonance imaging (MRI). Methods: Twenty patients with cleft-lip/palate, were clinically evaluated by RDC/TMD and by MRI. The ID of TMJ evaluate were disc displacement with reduction (DDWR) and disc displacement without reduction (DDWOR). Results: The present study showed that $9(45 \%)$ of the patients were diagnosed with ID of TMJ (8 [40\%] patients with DDWR and 1 [5\%] with DDWOR) and $11(55 \%)$ present no disorders, by RDC/TMD. MRI examination revealed that $15(75 \%)$ of the patients had ID of TMJ (13 [65\%] patients with DDWR and 2 [10\%] with DDWOR) and $5(25 \%)$ present no disorders. The Kappa index between the clinical and imaging diagnosis was 0.01 . Conclusion: In the present study, DDWR was diagnosed in $40-65 \%$ by the $\mathrm{RDC} / \mathrm{TMD}$ and MRI, respectively; DDWOR was diagnosed in $5-10 \%$ by the RDC/TMD and MRI, respectively. The diagnostic correlation between the clinical examination based on RDC and on MRI was weak.

Key-words: Cleft lip. Cleft palate. Temporomandibular joint dysfunction syndrome. Nuclear magnetic resonance. 


\section{Introduction}

Cleft-lip/palate is one of the most common craniofacial congenital deformities, being characterized by a flaw that occurs during the embryonic process of facial and palatine fusion ${ }^{1}$. Prevalence estimates show the occurrence of one case of cleft-lip/palate in every 700 live births in the world's population². Patients with cleft-lip/palate need early interventions from different medical areas such as speech therapy, orthodontic and/or surgical treatments, which are long and usually lasts until adulthood, being a burden to the patient, family and society ${ }^{3}$. Patients with cleft-lip/palate may present hearing loss that may be related to temporomandibular disorders (TMD) ${ }^{4}$. TMD are a group of musculoskeletal disorders that affect the temporomandibular joint (TMJ), masticatory muscles and associated structures ${ }^{5}$.

TMD diagnosis should be performed by anamnesis, along with physical and complementary examinations ${ }^{6}$. The Research Diagnostic Criteria for TMD (RDC/TMD) was the first standardized evidence-based diagnostic method for TMDs ${ }^{5}$. More complex cases need the use of imaging to help diagnostic confirmation. Magnetic resonance imaging (MRI) is considered the gold standard exam for TMJ conditions, since it allows the simultaneous evaluation of the morphology and position of the articular disc and bone structures of the $\mathrm{TMJ}^{7}$.

In the current literature, the prevalence of TMD range between $27.2 \%^{8}$ and $34.9 \%{ }^{9}$. Internal derangements (ID) of TMJ are some of the most common TMD conditions ${ }^{10}$. ID of TMJ are dysfunctions where there is an abnormal positional relationship between the disc and the condyle, articular eminence, and/or articular fossa ${ }^{11}$. Among ID, disc displacement with reduction (DDWR) corresponds to $41 \%$ of TMD clinical diagnoses ${ }^{12}$ and disc displacement without reduction (DDWOR) presents an estimated prevalence of $35.7 \%^{13}$. However, there has been no studies assessing the prevalence of ID in patients with cleft-lip/palate.

Therefore, the aim of this study was to estimate the prevalence of ID of TMJ in patients with cleft-lip/palate. Also, to evaluate the correlation of diagnosis between RDC/TMD clinical examination and MRI.

\section{MATERIALS AND METHODS}

The present study was approved by the Research Ethics Committee of the Clinical Hospital from Porto Alegre of the Federal University of Rio Grande do Sul ( $n^{\circ} 563331$ ). All the patients signed the Term of Informed Consent. The whole sample was clinically evaluated and diagnosed by the Unit of Craniomaxillofacial Surgery of the Porto Alegre Clinic Hospital (HCPA) - RS - Brazil. Sample size calculation was based on some similar studies ${ }^{14,15}$. The sample was comprised by 20 patients, from both genders, with cleft-lip/palate.

The inclusion criteria comprised individuals with complete or incomplete cleft-lip/ palate, uni- or bi-lateral, that were submitted to surgical procedures to the correction of the deformity. Individuals excluded from the research presented malignant neoplasm of head and neck, bony ankylosis, previous TMJ surgery, metal implants, 
heart valve, plates, pin, screw, stent, brain aneurysm clip, metal shrapnel, piercing, electronic implant (pacemaker, neurostimulator and cochlear implant), pregnancy suspicion, or claustrophobia.

All patients were first clinically evaluated by a dental surgeon calibrated to work according to RDC/TMD - Axis I, in the official Portuguese version. In a second moment, patients underwent an MRI. The MRI examinations were analyzed by the same experienced radiologist, according to the criteria defined by Ahmad et al. (2009) ${ }^{16}$. The ID of TMJ evaluate were DDWR and DDWOR.

\section{Statistical analysis}

A descriptive analysis was performed, average and standard deviation were calculated to the quantitative variable, and the categorical variables were expressed in frequency and percentage. Kappa index was used in the comparison of the clinical and the MRI diagnosis. Data were analyzed by SPSS version 20.0 for Windows ${ }^{\circledR}$ (Microsoft Corporation) and adopted alpha value was $5 \%$.

\section{RESULTS}

The sample was comprised by 20 patients, 14 (70\%) male and $6(30 \%)$ female. The relation between the genders was of $2: 1$ in this sample. The average age was of $12.35 \pm 2.5$ years. About the cleft-lip/palate type, five $(25 \%)$ had only cleft palate, three (15\%) had left cleft-lip/palate, three (15\%) had right cleft-lip/palate, and nine (45\%) of the patients presented bilateral cleft-lip/palate.

Results showed that $9(45 \%)$ of the patients were diagnosed with ID of TMJ (8 [40\%] patients with DDWR and 1 [5\%] with DDWOR) and 11(55\%) present no disorders, by RDC/TMD. MRI examination revealed that 15 (75\%) of the patients had ID of TMJ (13 [65\%] patients with DDWR and 2 [10\%] with DDWOR) and 5 (25\%) present no disorders.

Comparing RDC/TMD and MRI diagnosis, only five (5\%) individuals present no changes. Seven (35\%) patients presented changes in MRI but did not present clinical diagnosis. Four (20\%) patients were diagnosed in the RDC/TMD clinical examination, but no alteration was found in MRI. Eight (40\%) individuals presented changes in both examinations. The relation between the clinical and imaging diagnosis was weak, Kappa index of 0.01 , showing there is no agreement $(p>0.05)$ between the clinical diagnosis based on RDC/TMD and the MRI diagnosis.

\section{DISCUSSION}

The present study aimed to estimate the prevalence of ID of TMJ in patients with cleft-lip/palate, and to evaluate the correlation of diagnosis between RDC/TMD clinical examination and MRI. Etiological factors leading to ID of TMJ are partially attributed to abnormal biomechanical forces applied to the mandibular condyle, which alter the shape and function of the articular tissues ${ }^{17}$. ID conditions, such as disc-condyle complex derangement, can be related to several factors such as chronic (microtrauma) or acute injuries (macrotrauma) directed against the TMJ, shape and/or dynamic properties alterations of the TMJ components, lack of lubrication, the form of the disc 
modifications, degenerative articular disorder, some occlusal abnormalities, hyperactivity of the lateral pterygoid muscle, joint hypermobility, weakness or laxity of the TMJ ligament and joint capsule ${ }^{17,18}$.

In the present study, DDWR was diagnosed in $40-65 \%$ of the patients by the RDC/TMD and MRI, respectively; DDWOR was diagnosed in $5-10 \%$ of the patients by the RDC/TMD and MRI, respectively. In patients with DDWR, when the mouth is closed, the articular disc is displaced in relation to the condyle and, when the mouth is open, the disc returns to the intermediate area between the condyle and the articular tubercle ${ }^{19}$. The higher prevalence of DDWR is expected once this condition corresponds to $41 \%$ of all TMD clinical diagnoses ${ }^{12}$; also, it is commonly an asymptomatic condition and no treatment is usually required, since the structures in this region may adapt and the progression is extremely benign for most of the cases ${ }^{20}$. In DDWOR, the articular disc remaining anteriorly displaced relative to the mandibular condyle both with the mouth open and closed. DDWOR presents an estimated prevalence of $35.7 \%^{13}$ and may result in abnormal mechanical stresses and induction of inflammatory mediators within the $\mathrm{TMJ}^{21}$.

The relation between the clinical and imaging diagnosis was weak, Kappa index of 0.01, showing there is no agreement between the clinical diagnosis based on RDC/TMD and the MRI diagnosis. However, other study showed a fairly good (Kappa=0.63) agreement between clinical examination according to RDC/TMD and MRI for assessment of the disc-condyle relationship ${ }^{22}$. Sample size differences may have contributed to this divergence of results. The present study evaluated only 20 patients with a specific condition (cleft-lip/palate), while this other study work with 116 patients from a general sample 22 .

Some researchers ${ }^{23,24}$ have described a higher prevalence of TMD in women. Although this difference is still not well explained, some theories have tried to explain why women tend to be more affected than men. It is believed that estrogen can increase inflammatory hyperalgesia in the TMJ and have peripheral and central action in the modulation of pain, influencing the sensitization of the trigeminal system ${ }^{23}$, there is also a greater joint laxity, and greater intra-articular pressure ${ }^{24}$. However, the present study showed a higher incidence of TMD among men (70\%) in relation to women (30\%), this may be explained by the higher prevalence of clefts which involve lip and palate in the male sex ${ }^{25}$.

The relationship between cleft-lip/palate and TMD are not fully established. Although patients with cleft-lip/palate may present hearing loss related to TMDs ${ }^{4}$, the literature showed that the tube dysfunction present in these patients is not a triggering factor for TMJ dysfunction ${ }^{26}$. However, once there is a significant reduction of life quality of patients with specific subtypes of TMDs, such as ID of $\mathrm{TMJ}^{27}$, investigations of this conditions in a cleft-lip/palate population it is important to help these individuals. Future studies, with a larger sample, should be done to clarify if cleft-lip/palate patients present a higher prevalence of ID of TMJ and/or if they are more susceptible to develop these conditions.

In the present study, considering ID of TMJ in cleft-lip/palate patient, DDWR was diagnosed in $40-65 \%$ by the RDC/TMD and MRI, respectively; DDWOR was diagnosed in $5-10 \%$ by the RDC/TMD and MRI, respectively. The diagnostic correlation between the clinical examination based on RDC and on MRI was weak. 


\section{REFERÊNCIAS}

1. Crockett DJ, Goudy SL. Cleft lip and palate. Facial Plast Surg Clin North Am. 2014 Nov;22(4):573-86. doi: 10.1016/j.fsc.2014.07.002.

2. World Health Organization. International Classification of Diseases (ICD). Geneva, Switzerland: World Health Organization; 2012.

3. Silva MARD, Balderrama IF, Wobeto AP, Werneck RI, Azevedo-Alanis LR. The impact of nonsyndromic cleft lip with or without cleft palate on oral health-related quality of life. J Appl Oral Sci. $2018 \mathrm{Apr}$ 5;26:e20170145. doi: 10.1590/1678-7757-2017-0145.

4. Machado IM, Pialarissi PR, Minici TD, Rotondi J, Ferreira LP. [Relation of the Otological Symptoms in the Temporomandibular Dysfunctions]. Arq Int Otorrinolaringol. $2010 \mathrm{Jul} / \mathrm{Set} ; 14(3): 274-9$. Portuguese.

5. Dworkin SF, LeResche L. Research diagnostic criteria for temporomandibular disorders: review, criteria, examinations and specifications, critique. J Craniomandib Disord. 1992 Fall;6(4):301-55.

6. Ahmad M, Schiffman EL. Temporomandibular joint disorders and orofacial pain. Dent Clin North Am. 2016 Jan;60(1):105-24. doi: 10.1016/j.cden.2015.08.004.

7. Talmaceanu D, Lenghel Lm, Bolog N, Hedesiu M, Buduru S, Rotar H, et al. Imaging modalities for temporomandibular joint disorders: an update. Clujul Medical. 2018 Jul;91(3):280-7. doi: $10.15386 /$ cjmed-970.

8. Al-Khotani A, Naimi-Akbar A, Albadawi E, Ernberg M, Hedenberg-Magnusson B. Prevalence of diagnosed temporomandibular disorders among Saudi Arabian children and adolescents. J Headache Pain. 2016;17:41. doi: 10.1186/s10194-016-0642-9.

9. Bertoli FMP, Bruzamolin CD, Pizzatto E, Losso EM, Brancher JA, de Souza JF. Prevalence of diagnosed temporomandibular disorders: A cross-sectional study in Brazilian adolescents. PLoS One. 2018 Feb 8;13(2):e0192254. doi: 10.1371/journal.pone.0192254.

10. Schiffman E, Ohrbach R, Truelove E, Look J, Anderson G, Goulet JP, et al. Diagnostic Criteria for Temporomandibular Disorders (DC/TMD) for clinical and research applications: Recommendations of the International RDC/TMD Consortium Network and Orofacial Pain Special Interest Group. J Oral Facial Pain Headache. 2014 Winter;28(1):6-27. doi: 10.11607/jop.1151.

11. Murakami S, Takahashi A, Nishiyama H, Fujishita M, Fuchihata H. Magnetic resonance evaluation of the temporomandibular joint disc position and configuration. Dentomaxillofac Radiol. 1993 Nov;22(4):205-7.

12. Talaat WM, Adel OI, Al Bayatti S. Prevalence of temporomandibular disorders discovered incidentally during routine dental examination using the Research Diagnostic Criteria for Temporomandibular Disorders. Oral Surg Oral Med Oral Pathol Oral Radiol. 2018 Mar;125(3):250-9. doi: 10.1016/j.0000.2017.11.012.

13. Lazarin RD, Previdelli IT, Silva RD, Iwaki LC, Grossmann E, Filho LI. Correlation of gender and age with magnetic resonance imaging findings in patients with arthrogenic temporomandibular disorders: a crosssectional study. Int J Oral Maxillofac Surg. 2016 Oct;45(10):1222-8. doi: 10.1016/j.jom.2016.04.016.

14. Aiken A, Bouloux G, Hudgins P. MR imaging of the temporomandibular joint. Magn Reson Imaging Clin N Am. 2012 Aug;20(3):397-412. doi: 10.1016/j.mric.2012.05.002.

15. Kircos LT, OrtendahI DA, Mark AS, Arakawa M. Magnetic Resonance Imaging of the TMJ Disc in Asymptomatic Volunteers. J Oral Maxillofac Surg. 1987 Oct;45(10):852-4.

16. Ahmad M, Hollender L, Anderson Q, Kartha K, Ohrbach R, Truelove EL, et al. Research Diagnostic Criteria for Temporomandibular Disorders (RDC/TMD): development of image analysis criteria and examiner reliability for image analysis. Oral Surg Oral Med Oral Pathol Oral Radiol Endod. 2009 Jun;107(6):844-60. doi: 10.1016/j.tripleo.2009.02.023. 
17. de Leeuw R. Intra-articular derangements of the temporomandibular joint. Oral Maxillofac Surg Clin North Am. 2008 Jun;20(2):159-68. doi: 10.1016/j.coms.2007.12.004.

18. Okeson JP. Joint intracapsular disorders: diagnostic and nonsurgical management considerations. Dent Clin North Am. 2007 Jan;51(1):85-103, vi.

19. de Leeuw R, Klasser G. Orofacial pain: guidelines for assessment, diagnosis, and management. 6. ed. Quintessence; 2018.

20. Schiffman EL, Ahmad M, Hollender L, Kartha K, Ohrbach R, Truelove EL, et al. Longitudinal Stability of Common TMJ Structural Disorders. J Dent Res. 2017 Mar;96(3):270-6. doi: $10.1177 / 0022034516679396$.

21. Manfredini D, Basso D, Arboretti R, Guarda-Nardini L. Association between magnetic resonance signs of temporomandibular joint effusion and disk displacement. Oral Surg Oral Med Oral Pathol Oral Radiol Endod. 2009 Feb;107(2):266-71. doi: 10.1016/j.tripleo.2008.03.033.

22. Manfredini D, Guarda-Nardini L. Agreement between Research Diagnostic Criteria for Temporomandibular Disorders and magnetic resonance diagnoses of temporomandibular disc displacement in a patient population. Int J Oral Maxillofac Surg. 2008 Jul;37(7):612-6. doi: 10.1016/j.jom.2008.04.003.

23. Schmid-Schwap M, Bristela M, Kundi M, Piehslinger E. Sex-specific differences in patients with temporomandibular disorders. J Orofac Pain. 2013 Winter;27(1):42-50. doi: 10.11607/jop.970.

24. Bi RY, Ding Y, Gan YH. A new hypothesis of sex-differences in temporomandibular disorders: estrogen enhances hyperalgesia of inflamed TMJ through modulating voltage-gated sodium channel 1.7 in trigeminal ganglion? Med Hypotheses. 2015 Feb;84(2):100-3. doi: 10.1016/j.mehy.2014.12.010.

25. Luiza A, Noronha de Góis D, Santos JA, Brito de Oliveira RL, Ferreira da Silva LC. A descriptive epidemiology study of oral cleft in Sergipe, Brazil. Int Arch Otorhinolaryngol. 2013 Oct;17(4):390-4. doi: 10.1055/s-0033-1352502.

26. Manzi FR, Peyneau PD, Lopes AL, Silveira CL, Machado CSS, Ninno CQMS. Temporomandibular joint dysfunction and its correlation with auditory tube in cleft palate patients. Rev CEFAC. 2013 May/Jun;15(3):509-615. doi: 10.1590/S1516-18462013000300013.

27. Resende CM, Alves AC, Coelho LT, Alchieri JC, Roncalli AG, Barbosa GA. Quality of life and general health in patients with temporomandibular disorders. Braz Oral Res. 2013 Mar-Apr;27(2):116-21. 